\title{
REALITY CAPTURE CONNECTING PROJECT STAKEHOLDERS
}

\author{
Kevin McHugh ${ }^{1}$ Lauri Koskela ${ }^{2}$, and Algan Tezel ${ }^{3}$
}

\begin{abstract}
Digital media and point cloud captures have been used extensively in the mapping and surveying fields. As technology has advanced digital photographic and Lasor scanning information can be captured on site and processed rapidly. This has led to developing software that can use the processed information, for reconstructing it with the help of photogrammetric methods and connecting it to the 3D Building Information Model (BIM). This paper will review the effectiveness of reality capture digital process in a pandemic situation.

Reality Capture (RC) is becoming an important part of the information dynamics on construction projects. Lidar, Drone imagery, Laser scanning and Photogrammetry captures are now used extensively to document the construction process. Platforms that can, host, and overlay and compare scans and photographs to BIM models and 2D plans have been developed. RC provides a rich source of imagery that can also be used to support the production control process. Designers and project managers can focus on value added work utilizing the latest project imagery to co-ordinate and collaborate and to assist developing short term look ahead plans and validate prepared work plans. As a result of the Covid-19 pandemic worldwide societal and industrial shutdowns occurred the reduce the spread of disease. As industry returned safeguards had to be developed to protect workers and prevent the spread of disease. This paper outlines how a RC strategy that has been developed as a countermeasure to fragmented teams caused by the Covid-19 pandemic and how RC can be used to increase engagement by project stakeholders on construction projects in a post pandemic digital era. This paper discusses how digital tools can support established lean construction process and how action research can assist the continued development of new processes.
\end{abstract}

\section{KEYWORDS}

Reality capture, BIM, Last Planner® System, digital construction.

1 Associate Director, Construction Mace group. Kevin.Mchugh@ macegroup.com, orcid.org/0000-0002$\underline{6017-4585}$

2 Professor, School of Art, Design and Architecture, University of Huddersfield, UK, 1.koskela@hud.ac.uk, orcid.org/0000-0003-4449-2281

3 Senior Lecturer, Department of Architecture and 3D Design, University of Huddersfield, UK, a.tezel@ hud.ac.uk, orcid.org/0000-0003-3903-6126 


\section{INTRODUCTION}

Construction projects are complex, constantly evolving, task-based endeavours. As a result, the construction industry has been investing in technology to assist with project monitoring. Traditional project management methods have resulted in poor productivity with unpredictable results. The main reason for this is that modern projects consist of many fragmented teams and integrate supply chain dependencies(Bølviken and Koskela 2016,Dave et al. 2015a) Studies have highlighted the potential of using 3D mapping of construction sites and buildings from unmanned aerial systems (UASs) imagery to assist in management tasks (Golparvar-Fard et al. 2011). Providing a similar process to use imagery to map internal structures would boost productivity for internal works.

There is increased interest into digital visual management utilizing Building Information Modelling (BIM), Laser scanning and photogrammetric methods. These are not new technologies; however, the improvements of digital processing and storage provides greater connectivity and functionality for captured images. These methods include image-based sensing technologies (i.e., Reality Capture) and 3D remote sensing technologies (i.e., robotic total stations), Global Positioning Systems (GPS), Radio Frequency Identification (RFID), bar codes, Ultra-Wide Band (UWB) and laser and distance ranging - LADAR) (Golparvar-Fard et al. 2011).

Visual management (VM) is the practice of visualizing information or displaying requirements to set directions (Eaidgah et al. 2016). VM is used to support construction management such as production management, safety management, performance management, workplace management (housekeeping) (Tezel et al. 2016). Recent developments of vision engines and portable $360^{\circ}$ cameras have facilitated interior mapping technology that can be utilized internally in a building under construction (Pica and Abanda 2021). It is also possible to collect construction data using indoor positioning system. Data collection can be improved using Internet of Things (IoT) applications and real time imagery from drones and helmet cameras (Tang et al. 2019). A concern for data collection is that it can be often incomplete and inadequate (Zhong et al. 2015), where often only a fraction of operational disturbances are recorded in site meetings, and the progress reports, which can prevent effective communication.

As a result of the Covid-19 pandemic teams were dispersed and fragmented due to health restrictions. This disrupted the social interactive site based collaborative process. This paper will show how RC tools can support the Last Planner ${ }^{\circledR}$ System by providing the current situational picture. Mapping images to plans and further linking them to the model provides data that can be used rapidly for co-ordination as it reflects the current project conditions which improves the quality of the planning.

\section{LITURATURE REVIEW}

Lean methods and tools that can be supported using RC along with wider digital tools are reviewed to demonstrate how $\mathrm{RC}$ can support LC in a digital environment. The review of literature highlights how RC support social interactions and can support lean construction to improve the quality of communication and planning. 


\section{LEAN CONSTRUCTION}

Lean Construction (LC) is a holistic approach for managing construction projects, identifying the dependencies and promote collaboration between project stakeholders to manage the flow of information and work that is required to maintain effective work flow.Meetings are designed in a collaborative way where people gather in a 'big room' where interaction between project stakeholders is encouraged (Dave et al. 2015b). This process moved to virtual cloud-based meeting platforms. Meetings were carried out in a digital 'Obeya' room where collaborative planning was aided by digital visual management. Images, drawings, and 3D BIM models were used to inform and communicate planned works between trade contractors (Majava et al. 2019). The rooms help to arrive at decisions faster, provide a framework for waste elimination and asset logistical and sequencings issues.(Nascimento et al. 2018)

During the collaboration process, developing trust helps reduces tensions between stakeholders and altogether improving collaboration performance. Building trust can involve differing interpretations. For example, common understanding in business was seen as a fundamental factor in developing and accepting trust (Kasper-Fuehrera and Ashkanasy 2001). The review and presentation of current project imagery promotes real collaboration between teams.

\section{The Last Planner ${ }^{\circledR}$ System}

The Last Planner® System (LPS) (Ballard 2000)is used for managing production control on construction projects. The system relies on a collaborative management approach where tasks are co-ordinated collectively in short term cycles. Another key component is the review of Planned Percent Complete (PPC) which measures the effectiveness of the current planning cycle. This part of the system can be supported by utilizing visual management tools such as BIM, scanning and photographic imagery to provide unambiguous information that can be interpreted to support the planning process and provide the basis for highlighting areas of improvement (Xu et al. 2020).

\section{Visual MANAGEMENT}

Visual Management(VM) has an important role to play in providing clarity and availability of information, especially in face of the complexity of construction projects (Brady et al. 2018) Digital VM tools can acquire, sort and present large amounts of acquired project data in a form that can be easily accessed and interpreted by project stakeholders. Often a barrier for successful collaboration is the lack of information to accurately communicate the current project status to allow participants to collaborate and demonstrate productivity levels(Dave et al. 2010). The acquisition of sufficient amount and detail data is time consuming and as a result is not captured as regularly; usually, weekly, or monthly reports are gathered. The status information is not current, and it is not in a format that would help stakeholders (Soibelman et al. 2008).

The development of the BIM model is an integral component of the production control system. Properly developed and managed, BIM-centric project delivery makes available high fidelity, geometrically and positionally accurate, uniquely identifiable building component data sets together with a wealth of descriptive and operable metadata (Tang et 
al. 2019). The model is a collaborative platform which evolves in line with the construction programme.(Nascimento et al. 2018) The familiarity of the BIM model to all trade contractors allows facilitates the use of the model to assist collaborative meetings.

\section{Situational AWARENESS}

Ambiguity and a lack of the current situational awareness is a hindrance to LPS collaborative meetings, that often require follow up site meetings to verify or to replan short term work post meeting. Communication between stakeholders is inconclusive where quantities and make ready needs are not fully realised and therefore are not raised correctly.(Reinbold et al. 2020) Situational awareness can be supported by the collection and access to multiple picture files and access to real time images. This ability increases the productivity of management and trade contractors to access the correct information to support the decision-making process.

Utilizing RC platforms allows access to real time images which can be reviewed and analysed by all project teams at any time. The chronological arrangement and display of captured images are important. These images can be access and reviewed to provide insights into construction and design. This improves the quality of collaboration and improves communication channels which in turn reduce errors. This has increased project transparency which has increased the quality of collaboration and the effectiveness of meetings. If process transparency is successfully implemented, most problems, abnormalities, and types of waste that exist can be recognized to allow remedial measures to be taken (Saurin et al. 2008).

\section{CASE STUDY}

\section{Background to the Case Study}

The emergence of the Covid-19 pandemic in late 2019, affected Ireland in early 2020. As a result, a national lockdown was implemented to control the spread of the virus. This closed all non-essential workplaces including all construction project. To safely reopen construction projects measures were needed to be put in place to control the number of operatives on the project by introducing remote working for managerial staff and shift working for operational staff.

Increased team fragmentation was observed as a practical gap in the collaborative planning process which was used prior to the pandemic. This was a new constraint for the production planning process, both for the preparations and co-ordination of work plans and in the execution of these plans. This challenged the existing project production control system that relied on collaborative and social interaction for the preparation and execution of planned tasks. RC techniques that supported external work co-ordination capturing images using UAVs was identified as a possible solution, thus OpenSpace was identified to capture and use $360^{\circ}$ images for internal works.

To include remote teams all collaborative meetings were moved to on-line meeting platforms. Drone imagery and laser scanning has been used on the project and continued

to assist with external infrastructure planning. Internal images were captured by mounting a $360^{\circ} \mathrm{HD}$ camera on a hardhat and syncing your location to a floorplan to OpenSpace. 
Daily schedule of internal image capture walks quickly provided an extensive catalogue of $360^{\circ}$ images. These images were processed by 'OpenSpace' and displayed on a project plan for navigation and aligned to a BIM viewer for comparison. The first author conducted participatory action research to apply and combine digital tools to support the lean practices and visual management tools that were relied upon thus far on the project. Chevalier and Buckles (2013) contend that researchers contribute an important set of skills through their active involvement, including the ability to make sense of group dynamics and to identify the need for change. The first author managed the production control system for the project and was involved in the design and implementation of the production controls pre and post pandemic.

\section{Case Study Scope}

OpenSpace was the RC platform selected to capture and manage $360^{\circ}$ images for the project internal works. The project is a single storey Data Center that consisted of 8 data halls with an internal area of $57,000 \mathrm{~m} 2$ and administration building of $5,800 \mathrm{~m}^{2}$.

The pandemic imposed severe operational changes to the project with teams working remotely, split team rotas working on-site and offsite and teams that previously worked together split into shifts. The Covid-19 pandemic restricted the movements of key personnel to the project and similarly restricted the movements of on-site craft workers and supervision. Capturing $360^{\circ}$ images and syncing these images to the project floor plans and BIM model provided a digital creative space to collaborate, providing the ability to navigate through the project linking images with the floor plans and aligning the 3D model with the floorplan so that project photographs and model imagery could be compared.

\section{Production Control}

The basis of the project control system was to represent all aspects and review the current project activities and highlight dependencies with all project stakeholders. Design and technical information requirements were identified for project tasks where logistic and resource information were also required.

Pandemic restrictions meant that Design, Construction and Quality inspection teams were further fragmented. This challenged the existing collaborative production control system were project teams convened regularly. The existing system relied on face to face 'Big room' meetings. RC bridged the gap and allowed stakeholders to engage and interact and communicate effectively with each other. The challenge was to understand and present the production analysis data and relate this to work in progress. The availability of such massive data creates new opportunities to identify production bottlenecks and make an effective production plan through data-driven approaches (Posada et al. 2015) 


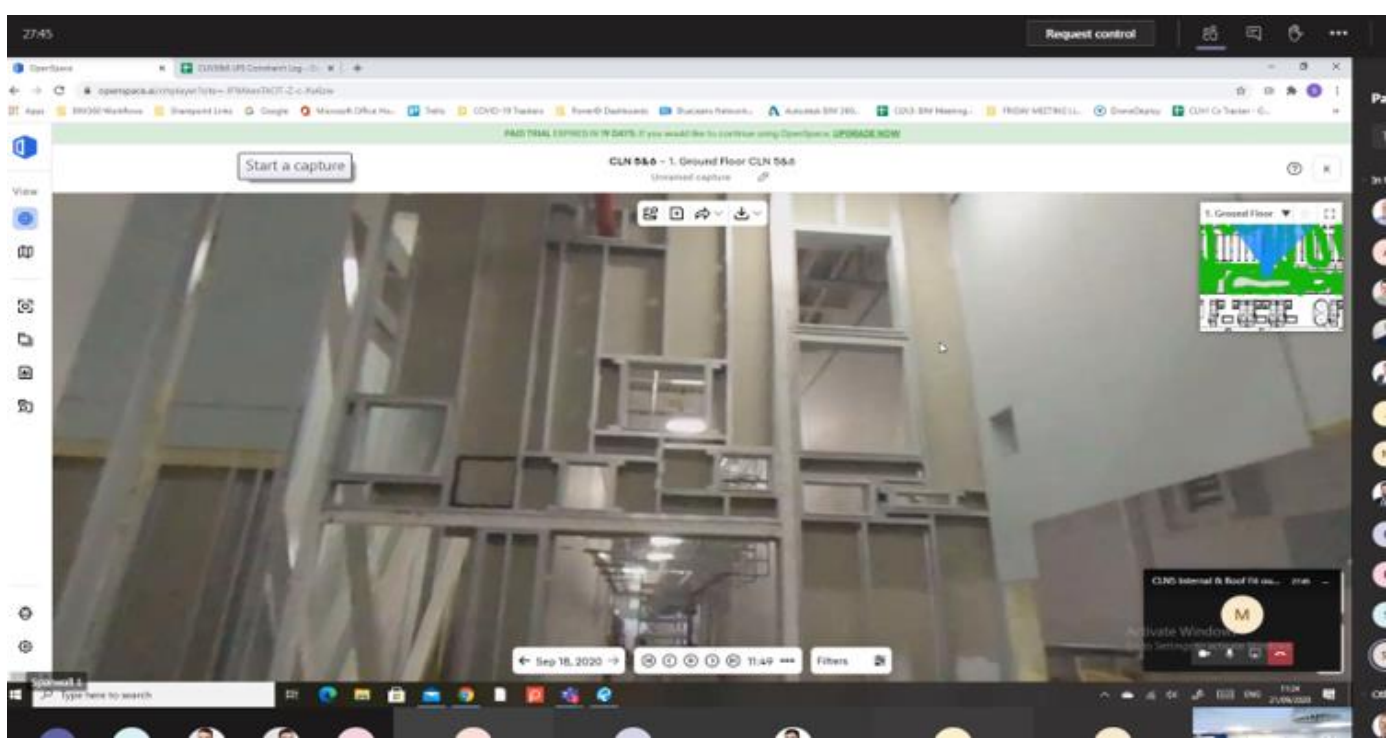

Figure 1 Virtual 'Big room' meeting

Area co-ordination could be maintained by all teams communicating using OpenSpace. Remote workers still operate effectively and communicate in area co-ordination meetings. This ensures all activities are planned and co-ordinated safely. Digital platforms were been used to produce short term planning and weekly planning activities to support the LPS. RC tools allowed teams to manage the look ahead planning and the review of planned percent complete (PPC) tasks. This assisted the improvement of work sequencing and sizing. Time and labour factors could also be discussed to manage labour utilisation and ensure operational safety. (see Figure 1).

This transparency improved the quality of the production plans. Supervisors could share their knowledge to address and communicate issues and opportunities. This increased the trust between project teams and allowed them to collaborate more effectively. The remote working virtual collaboration was highly visual, and the quality of the interaction was maintained by the immersive $360^{\circ}$ photographs and the comparison to the BIM model. This allowed discussions to flow as participants could navigate through the building virtually while comparing images to past images and the BIM model.

\section{Design Management}

A key principle for LC is to maximise value and minimise wastes. Design and inspection are critical functions for determining value. Design and technical product information approval are prerequisites for construction tasks. Managing the development of shop drawings and technical documents is key for maintaining a robust production control system.

$\mathrm{RC}$ connected design and construction teams to allow them to collectively manage and sequence design and co-ordination activities. As work progressed design teams can observe completed works and identify and communicate design requirements for the next planned construction phase. Look ahead planning for design activities mirrors the production look 
ahead so that design resources are efficiently utilized to ensure design activities are completed in advance of the planned construction activities.

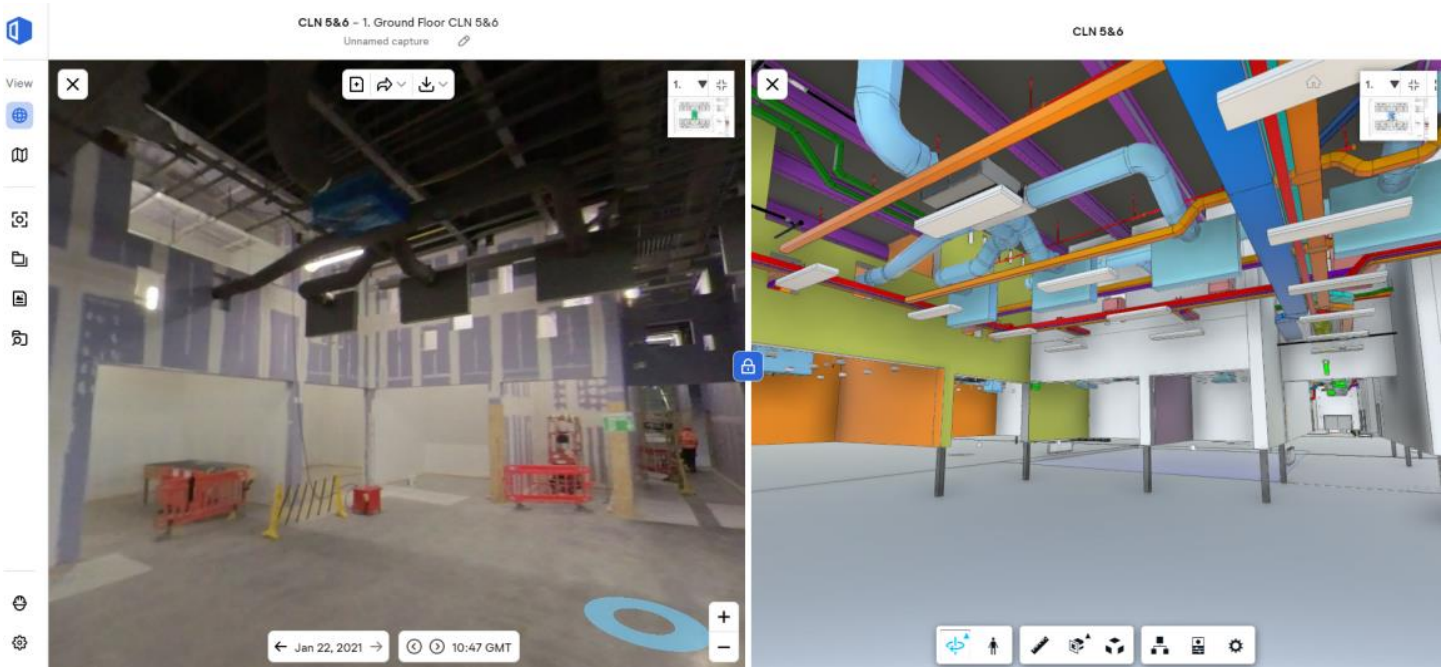

Figure 2 BIM Model Comparison

As part of the design quality reviews, the progress of construction tasks could be reviewed and updated in the design LPS where quality teams could review and confirm quality hold points, where follow on works cannot proceed without inspection of the preceding works. Therefore, inspections could be identified and scheduled in line with production plans to ensure continuity and progress tasks effectively (see Figure 2).

\section{DISCUSSION}

The deployment of the internal RC process was identified to fill a practical gap observed in the project management systems. RC successfully connected teams that were now working remotely or separated by different shift patterns. This reintegrated teams into the prevailing collaborative production management system that the project was successfully using prior to the pandemic. The ability to navigate virtually through the current state of the project increased the engagement between on-site and off-site teams by providing a common platform to review and understand the current situational picture.

The primary tool for production control is the LPS. Team engagement and commitment are critical for successful implementation of the system. RC supported the LPS allowing fragmented project teams to participate fully in the look ahead and review sections of the system. The trial was successful as the number of activities that were observed tracked and completed daily increased from the pre pandemic numbers and the planned percent complete (PPC) was unchanged and ranged from 70 to $80 \%$. The initial scope of the trial was quickly exceeded, and the images were introduced into project diaries and project status reporting.

RC has potential to further support the LPS by providing quantifiable metric comparing image captures providing quantifiable production information. The capture and processing times for these solutions have decreased rapidly, allowing quicker access to images, which 
assists an agile production control system by providing measurable production information that can be accessed and reviewed in near real time.

The use of RC underpins LC practices and supports a collaborative process. Utilizing the latest available data and imagery can improve accountability and therefore improve the engagement in the planning process. RC allows teams to evaluate and improve if is used in the right environment where continuous improvements are encouraged and supported. The simplicity of the software and the enhanced availability of information in the field and in the office allowed teams to interact together in a positive and collaborative manner. The availability of real time information allowed teams to effectively progress BIM meetings, package meetings and area co-ordination meetings, also considering that these collaborative meetings are attended by non-site-based personnel. It provides a large volume of valuable information that is accessible and easily interoperated. This supported the LPS, allowing teams to co-ordinate and communicate effectively and by providing a review of completed works that provided productivity insights.

However, the predominant current adversarial contracting arrangement does not allow full transparency which in turn restricts the access to information is an issue where teams would like greater access. With further maturity of collaborative contracting and the further digitization of construction, RC can effectively support planning design and execution of construction tasks.

The continued digitisation of construction will provide further digital integrations into project site management. Hybrid post pandemic solutions will embrace digital visual management and integrate these into hybrid visual management solutions. However, digitization should underpin the social collaborative LC approach where information is used to understand productivity rather than direct operational decisions using data alone. Where RC has increased transparency and can provide historic information to validate payments or intercede in dispute resolution it is important to protect the information and share it as a collaborative tool.

\section{CONCLUSION}

The deployment of OpenSpace was initiated to counteract the restrictions on movements of project team members. RC was proposed as a solution to continue to use LC effectively by reintegrating dispersed team members and allow them to continue to collaborate remotely. The platform was easy to use and required no additional onsite processing. The $\mathrm{RC}$ reviews formed part of each discipline's project meetings and increased the clarity of team communication.

The ability to interrogate images and to compare revisions of the image and the model browser function increased the situational awareness and allowed fragmented project to collaborate. The quality of the information increased the engagement between project stakeholders.

Digital construction and digital lean construction are at the cutting edge of industry innovations. Capturing and analyzing rich forms of data are coming into focus in the industry. Providing a lean philosophy of capturing enough information at the right time and presenting actionable data will connect fragmented construction teams and improve 
productivity. However, the large volume of competing platforms and management paradigms present a challenge to information management in construction.

This research was limited to using RC to support the LPS and collaborative planning. The author was responsible for the LPS on the project and potential improvements were noted anecdotally from other project disciplines. However, the potential to integrate RC into digitally management tools and providing near 'live' information can improve the effectiveness of all project operations. RC will remain an important addition to the digital management structure in the post pandemic era. Digital media will continue to evolve with further potential integrations of sensor technology and image recognition technology which also can be used to support LC in a digital era.

\section{REFERERENCES}

Ballard, H. G. (2000). "The last planner system of production control." $\mathrm{PhD}$ thesis, University of Birmingham, U.K.

Bølviken, T., and Koskela, L. (2016). 'Why Hasn't Waste Reduction Conquered Construction?' In:, 24th Annual Conference of the International Group for Lean Construction. Boston, Massachusetts, USA, 20-22 Jul 2016.

Brady, D. A., Tzortzopoulos, P., Rooke, J., Formoso, C. T., and Tezel, A. (2018). "Improving transparency in construction management: a visual planning and control model." Engineering, Construction and Architectural Management, Emerald Group Publishing Limited, Bradford, United Kingdom, 25(10), 1277-1297.

Chevalier, J. M., and Buckles, D. J. (2013). Participatory Action Research: Theory and Methods for Engaged Inquiry. Taylor \& Francis Group, London, United kingdom.

Dave, B., Boddy, S., and Koskela, L. (2010). Improving Information Flow within the Production Management System with Web Services.,18th Annual Conference of the International Group for Lean Construction, 14-16th July 2010, Haifa, Isreal.

Dave, B., Kubler, S., Pikas, E., Holmström, J., Singh, V., Främling, K., Koskela, L., and Peltokorp, A. (2015a). "Intelligent Products: Shifting the Production Control Logic in Construction (With Lean and BIM).” In:, Seppänen, O., González, V. A. \& Arroyo, P., 23rd Annual Conference of the International Group for Lean Construction. Perth, Australia, 29-31 Jul 2015,341-350.

Dave, B., Pikas, E., Kerosuo, H., and Mäki, T. (2015b). "ViBR - Conceptualising a Virtual Big Room through the Framework of People, Processes and Technology." Procedia Economics and Finance, 21, 586-593.

Eaidgah, Y., Maki, A. A., Kurczewski, K., and Abdekhodaee, A. (2016). "Visual management, performance management and continuous improvement: A lean manufacturing approach.” International Journal of Lean Six Sigma, Emerald Group Publishing Limited, 7(2), 187-210.

Golparvar-Fard, M., Bohn, J., Teizer, J., Savarese, S., and Peña-Mora, F. (2011). "Evaluation of image-based modeling and laser scanning accuracy for emerging automated performance monitoring techniques." Automation in Construction, 20(8), $1143-1155$. 
Kasper-Fuehrera, E. C., and Ashkanasy, N. M. (2001). "Communicating trustworthiness and building trust in interorganizational virtual organizations." Journal of Management, SAGE Publications Inc, 27(3), 235-254.

Majava, J., Haapasalo, H., and Aaltonen, K. (2019). "Elaborating factors affecting visual control in a big room." Construction Innovation, Emerald Group Publishing Limited, London, United Kingdom, 19(1), 34-47.

Nascimento, D., Caiado, R., Tortorella, G., Ivson, P., and Meiriño, M. (2018). "Digital Obeya Room: exploring the synergies between BIM and lean for visual construction management." Innovative Infrastructure Solutions, 3(1), 19.

Pica, D., and Abanda, F. H. (2021). "Emerging BIM-3D-Laser Scanning Integration in Construction Practice." Collaboration and Integration in Construction, Engineering, Management and Technology, Advances in Science, Technology \& Innovation, S. M. Ahmed, P. Hampton, S. Azhar, and A. D. Saul, eds., Springer International Publishing, Cham, 345-350.

Posada, J., Toro, C., Barandiaran, I., Oyarzun, D., Stricker, D., Amicis, R. de, Pinto, E. B., Eisert, P., Döllner, J., and Vallarino, I. (2015). "Visual Computing as a Key Enabling Technology for Industrie 4.0 and Industrial Internet." IEEE Computer Graphics and Applications, 35(2), 26-40.

Reinbold, A., Seppänen, O., and Peltokorpi, A. (2020). "The Role of Digitalized Visual Management to Empower Selfmanaged Crews in Construction Projects." Berkeley, California, USA, 925-936.

Saurin, T. A., Formoso, C. T., and Cambraia, F. B. (2008). "An analysis of construction safety best practices from a cognitive systems engineering perspective." Safety Science, 46(8), 1169-1183.

Soibelman, L., Wu, J., Caldas, C., Brilakis, I., and Lin, K.-Y. (2008). "Management and analysis of unstructured construction data types." Advanced Engineering Informatics, Intelligent computing in engineering and architecture, 22(1), 15-27.

Tang, S., Shelden, D. R., Eastman, C. M., Pishdad-Bozorgi, P., and Gao, X. (2019). "A review of building information modeling (BIM) and the internet of things (IoT) devices integration: Present status and future trends." Automation in Construction, 101, 127139.

Tezel, A., Koskela, L., and Tzortzopoulos, P. (2016). "Visual management in production management: a literature synthesis." Journal of Manufacturing Technology Management, Emerald Group Publishing Limited, 27(6), 766-799.

Xu, S., Wang, J., Shou, W., Ngo, T., Sadick, A.-M., and Wang, X. (2020). "Computer Vision Techniques in Construction: A Critical Review." Archives of Computational Methods in Engineering.

Zhong, R. Y., Huang, G. Q., Lan, S., Dai, Q. Y., Chen, X., and Zhang, T. (2015). “A big data approach for logistics trajectory discovery from RFID-enabled production data." International Journal of Production Economics, 165, 260-272. 